\title{
The Challenges of Quality Assurance in Private Higher Education Institutions in South Africa
}

\author{
Jacqueline Baumgardt \\ PhD Student: Department of Educational Leadership and Management \\ University of South Africa \\ jaybee@telkomsa.net \\ Mapheleba Lekhetho \\ Department of Educational Leadership and Management \\ University of South Africa \\ Email: lekhem@unisa.ac.za
}

\section{Doi:10.5901/mjss.2013.v4n3p421}

\begin{abstract}
Private providers operate in a complex educational environment in South Africa, which makes quality assurance cumbersome. The education authorities have gradually recognised that private providers have a valuable role to play in the provision of education and training in South Africa and the need to create a more enabling regulatory environment for private providers. To probe the views of stakeholders on the quality assurance challenges they face, the study adopted a mixed methods design collecting data from 93 research participants consisting of accreditation managers, the CEOs of professional bodies, the managers of quality assurance bodies and the Skills Universe Forum using online surveys and focus group discussion. The findings show that the majority of participants supported quality assurance mechanisms as they ensure delivery of quality education and training. However, some stakeholders are critical of the current complex regulatory framework. Hence, there is a call for a more streamlined system with a centralised oversight body, greater stakeholder consultation, less political interference and a deeper appreciation for the contribution that private providers make to education in South Africa.
\end{abstract}

Keywords: Globalisation, private providers, accreditation, quality assurance, marketisation

\section{Introduction}

Within the post-school private education sector in South Africa, there is a plethora of private tuition providers operating in Further Education and Training (FET) and Higher Education and Training (HET) institutions. According to Umalusi (2008:2), "FET private providers as a sector have not been intensively researched, either qualitatively or quantitatively" because state policy has tended to focus on public provision as a priority. Private higher education has also received little attention at a national level and has been viewed as competition for the public sector (Council on Higher Education [CHE], 2009). By law, private providers are required to be accredited (Further Education and Training Colleges Act, 2006; Higher Education Act, 1997), although many are not (Mining Qualifications Authority, 2011). In this sense, the post-school private education sector merits investigation.

Further Education and Training is provided for students who leave school at the end of Grade 9 or the age of 15, and is usually focused on vocational skills training, while Higher Education is offered at a post-matriculation level or after Grade 12. In January 2013 there were 87 accredited Private Higher Education Institutions (PHEI) and 31 provisionally accredited PHEls, offering a range of courses from certificates, diplomas to degrees in different fields such as health and beauty, theology, marketing, business skills, technology, arts and culture, to name a few, and some 974 private FET providers (Umalusi, 2013). The Association of Private Providers of Education, Training and Development (APPETD) (2009) claims to represent approximately 600 private providers in the Higher Education and Training (HET), FET, Adult Basic Education and Training (ABET) sectors including in-house training providers, distance education providers and training centres, with 600,000 learners on their books.

These providers may offer tuition for full qualifications, unit standards training, skills programmes, learnerships or short learning programmes, at different levels of the National Qualifications Framework (NQF) (Umalusi, 2008). Metcalfe (2010) corroborates that "the Government ... sees that there is an important role to be played by the private providers 
within the National Skills Development Strategy (NSDS) III" and that "there is ... a niche market for private providers and a need for private providers to address rapid response areas". However, the Chief Executive Officer of Umalusi, Dr Rakometsi expresses concern about private providers thus:

We are very concerned about the reputation of private provision in South Africa - private providers operating illegally exploit and mislead learners and this is very damaging to the whole private education sector - by this we mean independent schools, private FET colleges and adult learning centres (Umalusi 2010).

\section{Literature review}

Since the dawn of democracy in South Africa in 1994, there has been a massive shift in education toward upskilling large numbers of previously disadvantaged individuals (National Training Board, 2004). Three National Skills Development Strategies (NSDS), namely NSDS I (2000-2005), NSDS II (2005-2010) and NSDS III (2010-2015) have attempted to address this. Following on from the first two strategies, NSDS III (Department of Higher Education and Training [DHET], 2010) continues to emphasise the need for increased access to training and skills development opportunities in order to achieve the fundamental transformation of inequities linked to class, race, gender, age and disability still prevalent in South Africa. This is coupled with the imperative of meeting the educational needs of a fast-changing, more upwardly mobile society driven by "expansion, resource scarcity, increased competition, accountability to more stakeholders and the growing complexity of knowledge" (Mahlangu, 2008:1).

Furthermore, the globalisation and internationalisation of education has placed demands on education systems throughout the world for higher standards and better quality (Martin \& Stella, 2010), leading to the creation of quality assurance frameworks, underpinned by political ideologies, as well as quality assurance policies and practices. Since the 1990s, there has been an emphasis globally on quality assurance in education (Harvey, 2010), evidenced by many educational protocols, such as the Bologna Process, the Bruges-Copenhagen Process, the 'EU2020' Strategy, (all in Europe), the Brisbane Communique (in Australasia), ENLACES (in Latin America and the Caribbean), the African Higher Education Area (in Africa) and the SADC Protocol on Education and Training. South Africa joined the quality assurance movement with the establishment of the South African Qualifications Authority (SAQA) in 1995, and quality assurance has since become an important aspect of educational institutions and employers in South Africa.

New laws, policies and projects keep changing the quality assurance landscape and adding complexity to it (Patel, 2008). For example, each of the quality councils, the Department of Basic Education and the Department of Higher Education (formerly a single Department of Education) has devised its own criteria, quality assurance policies and processes, application forms, and monitoring systems. Until 2011, providers were expected to register with, and be accredited by, at least two different bodies. Since 2011, providers are required to register with, and be accredited by, only one of the quality councils, Umalusi, the Higher Education Quality Committee (HEQC) or the Quality Council for Trades and Occupations (QCTO).

According to the National Qualifications Framework (2013) accreditation refers to the process whereby "if an institution or provider meets the quality requirements laid down by the responsible body, it is therefore approved to carry out its functions and deliver what it says it can deliver". This may, or may not include learning programme approval because in some cases, accreditation and learning programme approval are required as two separate processes. Learning programme approval may be a condition for accreditation, while in other contexts accreditation may not involve learning programme approval. In other instances, some providers may be accredited by one body, but may need to submit study programmes for approval to a different body, complete and submit lengthy application documents, undergo audits, accommodate site visits using valuable resources. In contrast, public institutions are deemed to be accredited by law, irrespective of their performance or outputs. However, many debates in different forums point to deep systemic problems in the public education arena, such as inequalities in the school system (CHE, 2007), and dubious overall quality and quantity of graduate and research outputs within the higher education sector, and increased competition between institutions. It is also disconcerting that only $10 \%$ of matriculants achieve university entrance, university throughput rates are lower than 50\%, and the dropout and repetition rates are high, with students taking longer than four years to complete a bachelor's degree (Kadalie, 2011).

\subsection{Conceptual framework of quality assurance Management}

The Octet of Quality in Higher Education: Framework for Quality (Zaki, 2008) has been chosen to frame the discussion in this paper. However, this model does not present a complete picture as it focuses on a micro-level of quality assurance 
and only on higher education. The micro-level of quality assurance refers to the internal environment of the provider and the elements over which the provider has control and autonomy. Zaki's model reflected in Figure 1, has been expanded and modified to show that quality in education is influenced by the elements shown in the outer circle (or "macroenvironment"), all of which have an impact on the "micro-elements" which form the focus of quality assurance in education according to Zaki's (2008) model.

Figure 1: Micro- and macro-elements of quality assurance in education

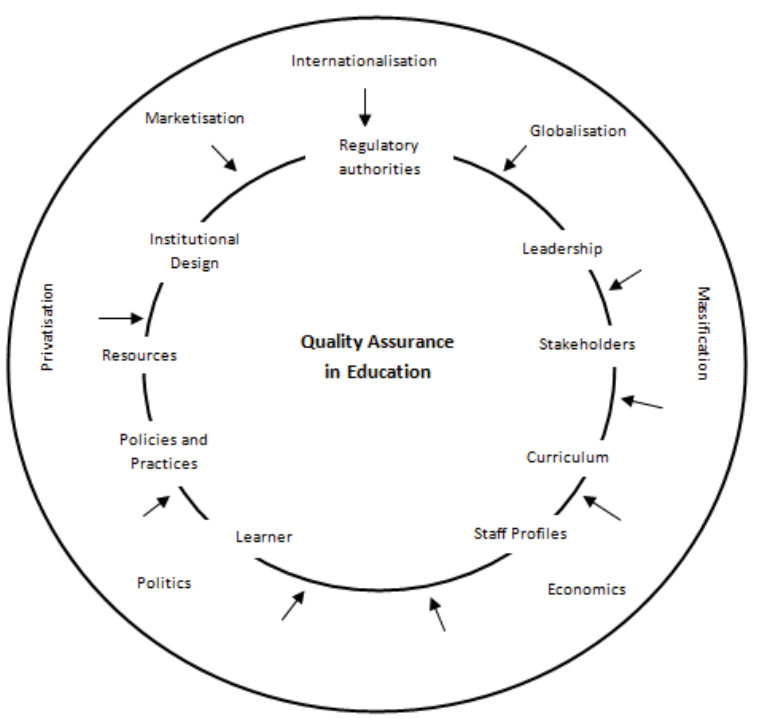

Source: Adapted from Zaki, 2008

\subsubsection{The micro-elements of quality assurance}

To understand what is really meant by quality in education the "micro-elements" of quality assurance are examined in this section. Farrington (2005:53) states that "we are not sure of what we mean by quality in ... education". This is because quality is an elusive concept. Normally, quality assurance and quality management are used in manufacturing industries to ensure that the products made are up to standard. Within education, however, quality assurance is generally concerned with achievements of learners at exit or qualification points. This is, however, a somewhat simplistic explanation since it ignores other social, democratic and citizenship goals of education.

In SAQA's implementation of a total quality system for the NQF, quality assurance, quality management and accreditation are not things or products; rather they are a continuous process (SAQA, 2000). In quality terms, the quality process includes the following critical aspects:

- The inputs: what the provider supplies in terms of programmes and learning resources. The quality of inputs and processes is the primary responsibility of Education and Training Quality Assurance bodies (ETQAs) and providers of learning.

- The process: the quality of the learning and assessment interactions; and the quality of the monitoring and auditing interactions.

- The outcomes: awards, achievement of standards or qualifications and accreditation.

\subsection{A stakeholder model of education}

The stakeholder model of education is a key concept in understanding the relationship between the private provider and the regulatory authorities within the context of the quality assurance regime. Stakeholder theory posits that businesses need to pay attention to their stakeholders. According to Phillips et al. (2003), stakeholder theory is an approach to 
organisational management and governance that includes a consideration of organisational stakeholders such as government departments, funders, companies, colleges and universities when making decisions. In essence, the theory is concerned with who the stakeholders are, how they can be identified, and their relative importance.

Hitt et al. (2001) define a stakeholder broadly as "any group or individual who can affect or is affected by the achievement of an organisation's purpose". For Roome \& Wijen (2006:2), stakeholders are "individuals or groups who significantly affect an organisation's behaviour". Thus, stakeholders are individuals or institutions who stand to gain or lose from the success or failure of a system, and include everyone who affects and is affected by policies, decisions or actions within that system (Freeman, et al., 2010). It is therefore, important that organisations undertake a stakeholder analysis to provide a framework against which a business can identify, evaluate, and incorporate stakeholder interests into their decision-making processes (Freeman, et al., 2010).

\subsubsection{The Importance of Stakeholder Theory}

The King III Report on Corporate Governance (IODSA, 2009) states that the board of a company should ensure that a company's code of ethics is developed, stipulating the ethical values or standards as well as more specific guidelines guiding the company in its internal and external stakeholders. Freeman (1984) maintains that attention to stakeholders is essential to effective strategic management in an increasingly complex world characterised by multiple groups and individuals that affect and are affected by organisational actions. Stakeholder analysis is used to identify and assess the importance of key people or institutions (Varvaskovszky \& Brugha, 2000). Gross and Godwin (2005) concur that stakeholder analysis creates a framework for the identification, evaluation, and incorporation of the various stakeholders' interests into organisational decision-making processes.

According to Jita (2006), the processes of stakeholder participation in the higher education quality assurance system have proven to be problematic with more of an authoritarian approach from the authorities as opposed to a true dialogue which results in mutual satisfaction or compromise. Although the notion of stakeholder engagement has been well reported in the business literature, it has not yet been fully realised in the field of education (Meyer \& Bushney, 2008). Ideally, educational institutions should also consider the ultimate consumer of their products, namely students, employers and the society.

\subsection{Globalisation, internationalisation and regionalisation}

Globalisation and internationalisation have a major impact on every area of life, from agriculture, to technology, to politics and education. They have created both challenges and opportunities in quality assurance in education to which countries and regions have responded in various ways, depending on their traditions, culture, resources and priorities (UNESCO, 2007). Narasaiah (2008) posits that the globalisation is accompanied by enormous costs as countries, particularly those in the developing world, deal with economic restructuring. In many cases, these countries are struggling to find the capacity to cope with these changes particularly in the educational arena (Chandra, 2007).

\subsubsection{Globalisation}

Burbules \& Torres (2000) note that there are so many varying opinions and perspectives on globalisation that no uniform definition of the phenomenon is possible. They contend that it is the effects of what is generally termed globalisation that are important, namely minimal state intervention, greater reliance on free market mechanisms, and "more appeal to individual self-interest than to collective rights" as well as a "growing integration of economies". Currie (1998:17) calls it an "economic ideology... that calls for the primacy of the market, privatization, and a reduced role for the public sphere" and it is seen as contributing to "social mobility and social justice" (Lee, 2000:325). Globalisation, that is well managed, has been seen to bring about healthy economic growth and prosperity (Suárez-Orozco \& Qin-Hilliard, 2004).

The educational arena has not been exempt from the effects of the globalisation phenomenon characterised by the increasing demand for higher quality education and increasing pressure on state resources to provide this (Woolridge, 2005). UNESCO (2007: 2) posits that globalisation is the outworking of a number of forces:

- the need for massification especially in developing countries;

- the increasing marketisation of higher education brought about by a need to meet the training requirements of industry as well as the increasing numbers of private providers; 
- the increasing importance of information and communication technologies in all spheres of life, including education; and

- the trend towards internationalisation of education including greater student and academic mobility.

UNESCO (2007) further states that a holistic view of the education system and all its levels - basic, secondary, and post-school education, should be evident in policy and actions related to improving access to higher education. The key to success in this regard is that education should meet the needs of the market in both local and global societies and should create an "awareness of global society" (Bloom, 2004:73). Understanding the interrelatedness of local and global societies is an essential skill required in the modern world if a country is to create for itself a competitive advantage in growing its economy and improving the lives of its citizens. Such skill and understanding can be developed through education.

\subsubsection{Internationalisation}

Internationalisation is defined as the process of bringing an international or intercultural dimension into an academic institution which affects teaching, research, curriculum, student support and service to communities (Kritz, 2006; Wildavsky, 2010). Internationalisation has been found to contribute positively to the development of human capital in that it provides for greater opportunities for employment and "fosters economic competitiveness" of a nation (Walsh, 2009:6). The growing belief that access to knowledge and education is a universal human right (Walsh, 2009) has contributed to this trend. However, it has also led to massive demand for education which has led to questions regarding capacity of governments to provide such education. The Global Forum on International Quality Assurance, Accreditation and the Recognition of Qualifications (UNESCO, 2007) debated the question of who would provide higher education on a mass scale in the future.

The Forum noted that there is a wide variety of new providers offering higher education programmes using multiple delivery modes, often making use of innovative and ever-advancing technological developments (UNESCO, 2007). The education market seems to be a lucrative one as "media companies, multinational companies, corporate universities, networks of universities, professional organisations, and IT companies" (ibid) seek to expand their reach and increase their shareholders' return on investment. The diverse provision by multiple providers is meeting the needs of the market and local and global societies, and has the potential to meet the demand by the millions of eager young learners.

Secondly, the learners attending such institutions are more varied in their age, socioeconomic status, motivation, interests and needs. For example, they may be returning to work after a period of unemployment and need to upgrade their skills or qualifications, or they could be changing careers and need to learn new skills or get a higher qualification (Field, 2006). This is called 'lifelong learning' which creates a need for broader access to a more varied range of courses and programmes (Field, 2006). In such a scenario, private providers would be needed as they are more flexible than a public provider in terms of what they offer. The procedures of changing the offerings by a public provider are lengthy and complicated and they might not be able to be as responsive to the market as private providers are. According to Garton (2010) private provision already accounts for over $30 \%$ of education around the globe, while Fielden (2010) has found that private provision is already higher education's fastest growing segment worldwide.

\subsubsection{Regionalisation}

Most quality assurance models are based on "national understandings of education systems" (UNESCO, 2007) which lead to problems in quality assurance within a region. The globalisation of education has given rise to the development of several regional protocols on quality assurance. All these initiatives and strategies are aimed at improving the quality of education generally within individual countries, and across regions of the world, as well as giving recognition to qualifications earned in foreign countries. The common denominator in all these initiatives is the need for collaboration, co-operation and cross-recognition of qualifications, particularly in the higher education arena, and a basic agreement that quality assurance should conform to the UNESCO Guidelines for Quality Provision in Cross-border Higher Education (UNESCO, 2005). However, there are still some wide variations in the key principles espoused by the various quality assurance frameworks (Stellar, 2008) and no absolute standard exists. This indicates some of the challenges specifically related to quality assurance, accreditation and the recognition of qualifications (UNESCO, 2007).

Every qualification registered on the National Qualifications Framework (NQF) is required to indicate its international comparability or equivalence in other countries. In general, people with qualifications acquired from South African institutions find a ready market for employment and career opportunities in foreign countries. However, it is 
difficult to determine how many of these qualifications emanate from public or private institutions. Therefore, a question that arises is, if these qualifications are accepted in foreign countries, why is articulation between South African countries difficult. It has proven difficult for students to transfer from one institution to another and to move up the NQF scale with due recognition of credits already earned (DHET, 2012).

\section{Methodology}

The study adopted a mixed methods research approach by integrating both qualitative and quantitative techniques for data collection and analysis. According to Brannen (2005:4), the methods may be "a mix of qualitative and quantitative methods, a mix of quantitative methods or a mix of qualitative methods". Mixed methods research also means working with different kinds of data. Spratt et al. (2004) see mixed methods as a 'third paradigm' distinct from the positivist perspective of quantitative research and the constructivist perspective of qualitative research. Mixed method designs provide the basis for triangulation and "become the source of different ways of conceptualising the problem" (Spratt, et al., 2004:8).

Data was collected by means of an online survey using a self-administered questionnaire on a convenience sample drawn from the private providers, namely principals or accreditation managers of accredited tuition providers, professional bodies and ETQA managers. The focus group discussion was conducted for members of the Skills Universe Forum subgroup called the "accreditation, training material, assessment" discussion group. Opportunity sampling was used because not all Sector Education and Training Authority (SETA) websites had the contact details of their providers readily available, and were unresponsive to requests for such information. The databases of 20 regulatory authorities were therefore used as the sampling frame.

Furthermore, volunteer sampling was used for the population of the Skills Universe forum on accreditation, training material, and assessment comprised of 318 ETD practitioners. Volunteer sampling is a "type of non-probability sampling that is most effective when one needs to study a certain cultural domain with knowledgeable experts within" (Tongco, 2007:147). One of the researchers is a member of this group and so it was through personal contact that this online focus group was created. Initially 23 people indicated that they would participate in the focus group. The discussion took place in an asynchronous fashion (Rezabek, 2000), because the participants were not sitting together in a room at the same time, but logged in to the focus group forum after being sent an email from the Skills Forum website, and answered the questions online as and when they had the time.

The SurveyGizmo.com website was utilised for the compilation and delivery of the online surveys because data is standardised and, therefore, relatively easy to analyse. The online surveys are relatively inexpensive and allow for data to be gathered quickly from a large number of respondents, and participants are assured of anonymity and confidentiality. However, one disadvantage of online surveys is that responses may be inaccurate, especially if the respondents misinterpret the questions in the self-completing questionnaires.

Table 1: Sample sizes and response rates

\begin{tabular}{|l|c|c|c|}
\hline & $\begin{array}{c}\text { Principals of private } \\
\text { tuition providers }\end{array}$ & CEO Survey & $\begin{array}{c}\text { ETQA Manager } \\
\text { Survey }\end{array}$ \\
\hline Distributed & 4996 & 39 & 23 \\
\hline Undeliverable & 1337 & - & 9 \\
\hline Returned questionnaires & 160 & 10 & 0 \\
\hline Rejected due to non-completion & 66 & 3 & 0 \\
\hline Final total for analysis & 93 & 7 & 0 \\
\hline Response rate & $2.5 \%$ & $17.9 \%$ & 0 \\
\hline
\end{tabular}

Although the response rates appear to be miniscule and unrepresentative, the target response rate needed for providers was 99, so 93 is not far below that target, and the statistical significance from the other target populations cannot be determined because of the small target populations. Non-response bias was mitigated by the large degree of overlap on the results (discussed below) between individual providers as well as the other research participants, and it is concluded that, because of the overwhelmingly similar findings, a higher response rate would not have made a significant difference.

The online focus group started out with 23 people indicating their willingness to participate but interest waned after the first couple of questions had been posted, and only 7 people consistently commented on the remaining questions. These were detailed comments provided by industry practitioners who have had first-hand experience of the accreditation 
and quality assurance regime. They are therefore a valuable source of triangulation for the findings of the survey results from the accredited tuition providers, as well as the semi-structured interviews conducted with the ETQA manager and professional body CEO.

A manual inductive approach geared to identifying patterns in the data by means of thematic codes was used (Hammond \& Wellington, 2013). Inductive analysis was applied to the qualitative information supplied in the surveys, the interview transcripts and the focus group transcript. This coding framework was confirmed as largely correct by an indepth and iterative analysis of the transcripts as well as on the qualitative answers arising out of the questionnaires, which highlighted the keywords and phrases and confirmed the relevance of the a priori coding framework. Quantitative analysis has been limited to tables and charts derived from the surveys which provide a picture of the private provider, and are then elaborated on in the qualitative discussion.

\section{Findings and discussion}

This section presents and discusses the findings of the study.

\subsection{Programme offerings}

An analysis of programme offerings shows that tuition providers offer different types of qualifications, with the larger organisations offering a greater number of each kind of qualification, and the bulk of smaller providers offering unit standards, skills programmes and short courses which range in duration from half a day to $1 \frac{1 / 2}{2}$ years. Many private providers do not offer whole qualifications (i.e. full-time, year-long programmes), but prefer to offer smaller and shorter, more tailored programmes to their clients, both students and employers. This is because employers find short, tailormade programmes more suitable for upskilling their staff than lengthy full-time courses. However, according to Sapa (2011), the Minister of Education and Training, Dr Blade Nzimande expressed concern that South Africa spends a considerable amount of skills development fund on short courses which are of 'dubious value' and reiterated that there is a need to strike a balance.

\subsection{Learner Profiles}

With respect to equity and access, the questions focused on race, educational background, socio-economic status, and demographic information like age and nationality. The majority of providers of all sizes (64 of the 93 respondents) cater for all race groups, with five stating that they only had white male learners and 24 stating that they catered almost exclusively for black students. Most providers (81), irrespective of size, have a mixed group of students, employed and unemployed, with only a few (12) stating that they had only unemployed or self-employed learners. The majority of providers (60) stated that they only have South African students, while 33 reported that their student populations included foreign students as well, mainly from South Africa's neighbouring states. These statistics are evidence that there is little discrimination on the basis of race, age or socio-economic status amongst the private providers, so equity cannot be regarded as a problem.

\subsection{ETQA Accreditation}

The questionnaire was sent to accredited private providers to determine which accrediting bodies they were linked to and their experiences across all the sectors and levels. The object of the question was to investigate whether the providers were spread across all industrial sectors and between the DHET, Umalusi and the QCTO. Interestingly, Table 2 reflects that $95.7 \%$ of the sample supported the idea of accreditation, while $94.6 \%$ said that quality assurance was a business imperative. The fact that both these processes are largely supported by these providers indicates their willingness to comply with the regulatory system that has been established. The Professional Body CEO and the ETQA manager also voiced their agreement that both processes are essential.

Table 2: Survey responses to statements on accreditation

\begin{tabular}{|l|c|c|c|}
\hline Statements & Yes & No & Responses \\
\hline I support the idea of accreditation. & $95.7 \%$ & $4.3 \%$ & 93 \\
\hline Accreditation adds value to my business. & $92.5 \%$ & $7.5 \%$ & 93 \\
\hline
\end{tabular}




\begin{tabular}{|l|c|c|c|}
\hline I use my accreditation status to market my courses. & $92.4 \%$ & $7.6 \%$ & 92 \\
\hline Accreditation is perceived with value by my clients. & $87.0 \%$ & $13.0 \%$ & 92 \\
\hline Accreditation has a beneficial effect on overall competitiveness of training providers. & $78.5 \%$ & $21.5 \%$ & 93 \\
\hline Accreditation should be an option for private providers. & $51.1 \%$ & $48.9 \%$ & 90 \\
\hline $\begin{array}{l}\text { Once a provider has been accredited, this should be sufficient unless there are } \\
\text { complaints about the organisation. }\end{array}$ & $67.0 \%$ & $33.0 \%$ & 91 \\
\hline Accreditation has helped us to improve our pass rates. & $34.8 \%$ & $65.2 \%$ & 89 \\
\hline Costs of accreditation should be borne by the government. & $56.2 \%$ & $43.8 \%$ & 89 \\
\hline $\begin{array}{l}\text { Costs of accreditation should be charged on a sliding scale depending on the } \\
\text { provider's annual turnover. }\end{array}$ & $54.4 \%$ & $45.6 \%$ & 90 \\
\hline
\end{tabular}

Surprisingly, the focus group, comprised of some unaccredited and accredited providers, freelance facilitators, assessors and moderators was divided on the issue of the need for accreditation. This question instigated a lengthy discussion with focus group members in favour of accreditation stating that they believe it is essential while those who were opposed to it stated that reputation and good service were what was needed since accreditation did not necessarily add value. Employers used the services of the accredited providers because the courses were short, tailor-made to the needs of the client and did not remove the employee from the workplace for extended periods. It should be pointed out that the provision of unaccredited programmes is not illegal per se - the illegality comes in when the provider purports to be accredited for the programmes it is offering. A provider might be accredited for some programmes, such as unit standards, whole qualifications and/or skills programmes, and use that as a marketing tool for their unaccredited short course offerings. This is what causes the criticism of private providers by the media, the regulatory authorities and the students.

Table 3: Survey responses to statements on quality assurance

\begin{tabular}{|l|c|c|c|}
\hline Statements & Yes & No & Responses \\
\hline Quality assurance is a business imperative for our organisation. & $94.6 \%$ & $5.4 \%$ & 93 \\
\hline A private provider should only need to be quality assured by one quality assurance body. & $76.1 \%$ & $23.9 \%$ & 92 \\
\hline As a private provider, we should be allowed to choose our own quality assurance model. & $59.1 \%$ & $40.9 \%$ & 93 \\
\hline The government has too much influence in private education and training. & $72.8 \%$ & $27.2 \%$ & 92 \\
\hline Site visits are an essential part of an accreditation audit. & $89.1 \%$ & $10.9 \%$ & 92 \\
\hline Audits should be conducted by independent consultants not by ETQA officers. & $46.7 \%$ & $53.3 \%$ & 92 \\
\hline A single version of the accreditation audit tool should be used in all sectors. & $68.9 \%$ & $31.1 \%$ & 90 \\
\hline There should be different accreditation requirements for small providers. & $56.5 \%$ & $43.5 \%$ & 92 \\
\hline There is sufficient stakeholder consultation by the ETQAs regarding quality assurance. & $34.4 \%$ & $65.6 \%$ & 93 \\
\hline $\begin{array}{l}\text { There is consistency of quality assurance practices or measures within the ETQA, e.g. } \\
\text { different verifiers or programme evaluators have the same interpretations. }\end{array}$ & $27.2 \%$ & $72.8 \%$ & 92 \\
\hline $\begin{array}{l}\text { Programme evaluators should be academically qualified in the programme they are } \\
\text { evaluating. }\end{array}$ & $93.5 \%$ & $6.5 \%$ & 93 \\
\hline Quality assurance has helped us to improve our pass rates. & $38.9 \%$ & $61.1 \%$ & 90 \\
\hline
\end{tabular}

Table 3 indicates that the majority of respondents, $94.6 \%$ support quality assurance, confirming the statement that it is crucial for their organisations, possibly because it served as a seal of quality for their programmes and helped them to improve them. This could simultaneously serve as a marketing tool for their programmes. A significant percentage agreed with the statement that the private provider should be quality assured by one assurance body. This reflects a possible disgruntlement with the current scenario where there are several assurance councils with onerous requirements, inconsistent application of the criteria, and the bureaucratic "tick-the-box" approach applied by the ETQA staff tasked with evaluating the provider's accreditation applications and the ongoing monitoring of quality assurance.

The survey showed that providers offered a mixed bag of courses. The mix of offerings also reflects the size of the organisation with the survivalist providers at the lower end of the spectrum offering only one or two unit standards and short courses, while the large providers at the top end of the spectrum offer multiple unit standards, whole qualifications, short courses, skills programmes and learnerships as shown in Table 4. 
Table 4: Numbers of providers and range of courses offered

\begin{tabular}{|c|c|c|c|c|c|}
\hline & $\begin{array}{c}\text { Whole } \\
\text { qualifications }\end{array}$ & $\begin{array}{c}\text { Unit } \\
\text { standards }\end{array}$ & $\begin{array}{c}\text { Short } \\
\text { courses }\end{array}$ & $\begin{array}{c}\text { Skills } \\
\text { programmes }\end{array}$ & Learnerships \\
\hline Percentage & $53.80 \%$ & $74.20 \%$ & $53.80 \%$ & $57.00 \%$ & $44.10 \%$ \\
\hline Number of providers & $58 / 93$ & $80 / 93$ & $58 / 93$ & $61 / 93$ & $47 / 93$ \\
\hline
\end{tabular}

The fact that many short courses are not accredited was, however, pointed out as a problem by one member of the focus group who stated that "a serious deficiency" of an integrated system is not recognising short courses, as employers need "a system where their employees can accumulate credits towards a national qualification by attending short courses".

\subsection{The survey for CEOs of professional bodies}

As indicated earlier, there were seven completed responses out of 35. Two of the seven indicated that they were accredited by the QCTO while the remaining five said that they were not accredited by any of the Quality Councils. Two of the latter five said that they wished to be accredited by the QCTO, while the two that are accredited by the QCTO stated that they would rather be accredited by the $\mathrm{CHE}$, and one that is not currently accredited also wished to fall under the $\mathrm{CHE}$. The remaining two participants did not indicate their choice.

All the participants indicated that they were not registered with the DHET, which is to be expected, since in terms of the NQF Act, 2008, professional bodies are not permitted to be registered as training providers. Three of the participants stated that they were quality assured by FASSET, with one linked to each of HWSETA, MICT SETA and SASSETA with the last one not yet accredited by any specific SETA. In the main, these professional bodies have not yet accredited any providers except for one which has accredited eight providers and another which has accredited five. It was a different story when it came to the accreditation of workplace providers where one of the professional bodies indicated that it had accredited approximately 800 such providers. The majority of providers in all sectors fell into the small to world-competitive small scale in terms of SAQA's classification (SAQA, 2004), with no survivalist providers indicated, and fell into the FET and HET bands in terms of the programmes they offer.

\section{Conclusion}

Upon the introduction of democratic rule in 1994, the new Government prioritized education as one of the sectors that needed to be fixed. To regulate the sector, quality assurance was introduced by creating the National Qualifications Framework, and private providers that had previously existed without any regulatory control, came under the spotlight and were expected to meet the accreditation and quality assurance standards established under the auspices of South African Qualifications Authority (SAQA). The study has established that these arrangements are largely embraced by the private providers who almost unanimously agreed that both accreditation and ongoing quality assurance are essential. One of the problems highlighted by the focus group was the continued existence of "fly-by-night" operations. While the mainstream private providers have welcomed being accredited and the concomitant quality assurance, there is still exploitation of learners taking place by unaccredited organisations.

Finally, the study has shown that private providers play a critical role at every level of post-school education especially because the government cannot afford to bear the full cost of education. Private providers cater for approximately $10 \%$ of the educational provision in South Africa over a wide range of programmes that public institutions cannot offer more specifically the skills programmes and short courses that effectively meet the needs of employers who want to upskill their workforces. Due to their business orientation and a greater focus on their stakeholders' requirements private providers have the ability to be more flexible in their offerings.

\section{Recommendations}

The study has revealed that there are many players in the private higher education sector, which leads to lack of coordination and common understanding. Hence, there is need for a common definition of quality assurance and a standard procedure for how it should be executed. Furthermore, the processes and procedures should be streamlined, simplified and standardised, and linked to the integrated National Qualifications Framework (NQF) to make the quality assurance process more efficient, to promote portability of credits and qualifications between learning institutions. This can be achieved if there is an integrated quality assurance framework, ideally under the auspices of SAQA. 
It is recommended that the SETA systems be overhauled as most SETAs do not seem to understand that they were primarily established to address skills shortages that exist in the South African economy. Accreditation and quality assurance should not be left in the hands of the SETAs since these have faltered because of a culture of ineptitude, bureaucracy, nepotism and cronyism. The focus of SETAs should shift from employers and other favoured service providers to learners and eligible training providers with the best practice in place.

It is also recommended that all levels and types of training, namely unit standards, whole qualifications, skills programmes and short courses be accommodated in the quality assurance framework. Most employers cannot enrol their employees for learning programmes of long duration and they need a system where their employees can accumulate credits towards a national qualification by attending short courses. Presently short courses do not generally have credits attached to them and a mechanism should be put in place whereby learners can accumulate credits, irrespective of the form of training they undergo.

Finally, stakeholder engagement is crucial to the success of any accreditation or quality assurance system. Currently, there is very little stakeholder involvement, and input from stakeholders does not seem to have any impact on the policies devised by the regulatory authorities. Industry practitioners should be involved in the evaluation of material content, delivery and assessment, and the ETQAs should have the responsibility of external moderation and learner certification.

\section{References}

Bloom, D. (2004). Globalization and education. In M. M. Suárez-Orozco, \& D. B. Qin-Hilliard (Eds.), Globalization: Culture and Education in the New Millennium (pp. 56-77). Los Angeles: University of California Press.

Burbules, N. C. and Torres, C. A. (eds.) (2000). Globalization and education: critical perspectives. London: Routledge, Taylor and Francis Group.

Chandra, R. (2007). Web-based education. Delhi: Kalpaz Publications.

Council on Higher Education. (2007). A case for improving teaching and learning in South African higher education. Higher Education Monitor, No. 6. Pretoria: Council on Higher Education.

Council on Higher Education. (2009). The state of higher education in South Africa.A report of the CHE advice and monitoring directorate. Higher Education Monitor, No. 8.Pretoria: Council on Higher Education.

Currie, J. (1998). Globalization practices and the professoriate in Anglo-Pacific and North American universities. Comparative Education Review, 42(1), 15-29.

Department of Higher Education and Training. (2010). NSDSIII framework, draft (1) for consultation, 29/04/10. [Online] Available: http://www.info.gov.za/view/ DownloadFileAction?id=121537 (February 17, 2012)

Department of Higher Education and Training. (2012). The green paper for post-school education and training. Pretoria: Department of Higher Education and Training.

Farrington, D. (2005). Legislative initiatives in the context of the Bologna process: a comparative perspective. In D. Lincoln (Ed.), Papers on Higher Education (pp. 5-67). Paris: UNESCO.

Ferreira, A. (2010). R175bn syphoned away. [Online] Available: http://www.timeslive.co.za/business/article412922.ece/R175bnsyphoned-away (August 22, 2011)

Field, J. (2006). Lifelong learning and the new educational order. Staffordshire: Trentham Books.

Fielden, J. (2010). The growth of private and for-profit higher education providers in the UK. London: Universities UK.

Freeman, R. E. (1984). Strategic management: A stakeholder approach. Boston: Pitman.

Freeman, R. E., Jeffrey S. Harrison, J. S., Wicks, A. C., Bidhan L., Parmar, B. L. and De Collen, S. (2010). Stakeholder theory: The state of the art. Cambridge: Cambridge University Press.

Further Education and Training Colleges Act, 2006 No 16 of 2006 (Republic Of South Africa), Pretoria: Government Printer.

Garton, J. (2010). Public and private alliances in TNE International and Development. Victoria: RMIT University Melbourne.

Gross, K. and Godwin, P. (2005). Education's many stakeholders. [Online] Available: http://www.universitybusiness.com /viewarticle.aspx?articleid=174 (August 21, 2011).

Hammond, M. H. and Wellington, J. J. (2013). Research methods: The key concepts. Abingdon: Routledge

Harvey, L. (2010). Twenty years of trying to make sense of quality assurance: the misalignment of quality assurance with institutional quality frameworks and quality culture [Online] Available: http://www.eua.be/Libraries/EQAF_2010/WGSII_7_Papers Harvey.sflb.ashx (March 24, 2012)

Higher Ëducation Act, 1997, No 101 of 1997 (Republic of South Africa), Pretoria: Government Printer.

Hitt, M. A., Freeman, R. E., \& Harrison, J. S. (Eds.). (2001). The Blackwell Handbook of Strategic Management. Oxford: Wiley-Blackwell. Institute of Directors in Southern Africa. (2009). The King report on corporate governance for South Africa. Johannesburg: Institute of Directors in Southern Africa.

Jita, L. C. (2006). Theorizing stakeholder participation within the higher education quality assurance system in South Africa. South African Journal of Higher Education, 20(6), 924-931. 
Kadalie, R. (2011). The dumbing down of our youth [Online] Available: http://www.politicsweb.co.za/politicsweb/view/politicsweb /en/page71619?oid=240071\&sn=Detail\&pid=71619 (September 22, 2012)

Kritz, M. M. (2006). Globalisation and internationalisation of tertiary education. Paper presented at International Symposium on International Migration and Development. Turin, Italy: United Nations Secretariat.

Lee, N. N. (2000). The impact of globalization on education in Malaysia. In N. P. Stromquist, and K. Monkman (Eds.), Globalization and Education: Integration and Contestation across Cultures (pp. 315-332). Lanham: Rowan and Littlefield.

Mahlangu, E. (2008). Quality assurance in higher education in Southern Africa: The case of the Universities of the Witwatersrand, Zimbabwe and Botswana. PhD Thesis, Unpublished. University of the Witwatersrand, Johannesburg.

Martin, M. and Stella, A. (2010). External quality assurance: options for higher education managers in CIS and South-East European countries. Paris: UNESCO.

Metcalfe, M. (2010). NSDSIII - Summit 8 June 2010 - A summary [Online] Available: http://viragoconsulting.com/2010/06/14/nsdsiii\%E2\%80\%93-summit-8-june-2010-a-summary/ (March 30, 2012)

Meyer, M. H. and Bushney, M. J. (2008). Towards a multi-stakeholder-driven model for excellence in higher education curriculum development. South African Journal of Higher Education, 22(6), 1229-1240.

Mining Qualifications Authority. (2011). MQA Accredited Providers Forum. [Powerpoint Presentation] August 26, 2011. Mining Qualifications Authority, Gauteng.

Narasaiah, M. L. 2008. Education and globalisation. New Delhi: Discovery Publishing House.

National Qualifications Framework (NQF). (2013). Frequently asked questions [Online] Available: http://www.nqf.org.za/page/faq/index (March 31, 2012)

Patel, R. (2008). 'Getting training right beyond 2010'. Paper presented at the First Pan African FET and TVET Conference, 08 August, Cape Town: The International Association of Colleges (IAC).

Phillips, R., Freeman, R. E. and Wicks, A. C. (2003). What stakeholder theory is not. Business Ethics Quarterly, $13(4), 479$ - 502.

Rezabek, R. J. (2000). Online focus groups: electronic discussions for research. Forum: Qualitative Social Research, 1(1), Art. 18.

Roome, N. J. and Wijen, F. 2006. Stakeholder power and organizational learning in corporate environmental management. Organization Studies, 27(2), 235-263.

Sapa. 2011. Short courses are of "dubious value" [Online] Available: http://www.moneyweb.co.za/moneyweb-political-economy/shortcourses-are-of-dubious-value (July 17 2013)

SAQA. (2004). Guidelines for the equitable accreditation of small-, medium and micro enterprise providers of education and training. Pretoria: South Africa.

SAQA. 2000. The National Qualifications Framework and quality assurance. Pretoria: SAQA.

Smith, M. K. (2002). Globalization and the incorporation of education [Online] Available: http://www.infed.org/biblio/ globalization_and_education.htm (July 22, 2011)

Spratt, C., Walker, R. and Robinson, B. (2004). Mixed research methods [Online] Available: www.col.org/resources /trainingresources/Pages/ PREST.aspx (March 18, 2012).

Stellar, A. (2008). Quality assurance arrangements in higher education in the broader Asia-Pacific region. Melbourne: Asia-Pacific Quality Network Inc.

Suárez-Orozco, M. M. and Qin-Hilliard, D. B. (2004). Globalization: culture and education in the new millennium. Los Angeles: University of California Press.

Tongco, M. D. C. (2007). Purposive sampling as a tool for informant selection. Ethnobotany research \& applications, 5,147-158.

Umalusi. (2008). FET private providers site visit and verification report. Pretoria: Umalusi.

Umalusi. (2010). Umalusi calls on fly-by-nights providers to get legal [Online] Available: http://www.umalusi.org.za/ur/publications/ 20110113AccreditationofProviders.pdf. (March 31, 2011).

Umalusi. (2013). Accredited providers [Online] Available: http://www.umalusi.org.za/lnveloper.asp?iP=157\&iVdate=07/04/2013\&iS $=\{$ A24CF241-AC12-4A2E-B8A7-607053896436 $\}$ (February 15, 2013)

UNESCO. (2005). Guidelines for quality provision in cross-border higher education. Paris: UNESCO.

UNESCO. (2007). External quality assurance: options for higher education managers [Online] Available: http://www.unesco.org/iiep/PDF/TR_Mods/HE_Mod2.pdf (March 30, 2011).

Varvaskovszky, Z. and Brugha, R. (2000). How to do (or not to do) ... a stakeholder analysis. Health Policy and Planning, 15(3), 338345.

Walsh, P. (2009). Global trends in higher education, adult and distance learning. Oslo: International Council for Open and Distance Education.

Wildavsky, B. (2010). The great brain race: how global universities are reshaping the world. New Jersey: Princeton University Press. Woolridge, A. (2005). The brains business [Online] Available: http://www.economist.com/node/4339960 (June 8, 2011).

Zaki, S. (2008). 'Parameters of quality in higher education: a theoretical framework', 2nd International Conference on Assessing Quality in Higher Education, Lahore, December 1-3. 
